\title{
REPRESENTACIÓN Y DEMOCRACIA
}

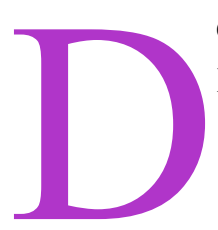

eseo referirme al problema de la justificación ética de la representación parlamentaria en la sociedad democrática moderna. Se trata, pues, de la legitimidad de una institución surgida en un momento dado de la historia europea como recurso técnico para asegurar la vigencia de los derechos y libertades de una determinada clase social: la burguesía. Como esta vinculación genética entre institución y clase social ha solido servir de base para decretar el carácter anacrónico de aquélla una vez que desaparecieron las condiciones político-sociales que le dieron origen, conviene hacer una breve referencia a los argumentos que se esgrimieron en su hora a su favor y que luego fueron tomados también en cuenta para criticar el Parlamentarismo democrático. Edmund Burke y Carl Schmitt pueden ser aquí buenas guías (I). Me interesa, segundo, exponer algunos puntos centrales del fundamento democrático del parlamentarismo. Para ello recurriré a dos estudios ya clásicos de Hans Kelsen (II). Por último, la confrontación de estas dos posiciones pienso que puede permitir sacar algunas conclusiones acerca de la justificación y los límites ético-políticos de la representación parlamentaria democrática (III).

\section{I}

Edmund Burke es, quizás, uno de los teóricos de la representación parlamentaria que con mayor claridad ha expuesto la vinculación entre parlamento y burguesía, atribuyéndole a esta última, en virtud de su cultura y su status económico, condiciones óptimas para asumir la representación general de la nación. Como es sabido, según Burke, la tarea del representante consiste no sólo en adoptar resoluciones legislativas técnicamente adecuadas, sino también éticamente correctas. Esta corrección ética presupone la existencia de verdades ético-políticas y de criterios 
que permitan verificar o falsear los enunciados que pretenden formularlas.

Precisamente porque existen respuestas moralmente correctas a los problemas políticos, existe una obligación moral de descubrirlas. El gobierno no es primordialmente un asunto de la voluntad, sino de la razón y la sabiduría. Y el parlamento es el foro donde, a través de la discusión pública, de la deliberación racional, es posible descubrir la verdad. Esta coincide con el interés nacional que, cuando es satisfecho, aprovecha también a cada miembro de la comunidad. A diferencia de Mill, Burke no consideraba que cada cual es el mejor juez de sus propios intereses; no existe, por tanto, una relación necesaria entre lo que la gente desea y la satisfacción de sus propios intereses. En consecuencia, no tiene sentido consultar al representado acerca de lo que debe hacerse en el parlamento, ya que sólo el representante está presente en las sesiones del parlamento, es decir, participa en la búsqueda de la verdad; por ello podía decir Burke:

«¿Qué clase de razón es esa en la que la determinación precede a la discusión, en la que un conjunto de hombres delibera y otro decide, y donde los que toman las decisiones están quizás a trescientas millas de distancia de aquellos que escuchan los argumentos?» (1949, $115)$.

Si el gobernar es un ejercicio de la razón y no de la voluntad, la voluntad del pueblo no puede tener un status especial. El pueblo debe conceder a los representantes la mayor libertad para que actúen como juzguen conveniente. El representante que sacrifica su juicio a la opinión de los electores «les traiciona en lugar de servirles» (ibidem). En su famoso discurso a los electores de Bristol, Burke había dicho:

«El parlamento no es un congreso de embajadores con intereses hostiles y diferentes, que cada uno debe sustentar como un agente y un abogado frente a otros agentes y abogados, sino que el parlamento es la asamblea deliberadora de una nación con un interés, el de la totalidad, donde los prejuicios locales no deberían servir de guía, sino el bien general resultante de la razón general de la totalidad.» $(1949,116)$.

La discrepancia entre interés y voluntad está relacionada con otra distinción burkeana: la que existe entre interés y opinión. El interés objetivo de un distrito electoral es distinto de las opiniones de alguno o incluso de todos los ciudadanos de un distrito. La opinión tiende a ser precipitada, vehemente, llena de 
prejuicios, sujeta a grandes y efímeras fluctuaciones. La opinión es subjetiva y contiene, por ello, una buena dosis de irracionalidad. El interés, en cambio, es objetivo y racionalmente fundamentable en la deliberación parlamentaria. El pueblo se encuentra en una situación desventajosa para descubrir su propio interés porque no puede participar en las reuniones parlamentarias. Sólo el transcurso del tiempo puede traer consigo una coincidencia entre las resoluciones parlamentarias y la opinión. El parlamento «imita en la esfera del gobierno el carácter natural de la sociedad como un todo» $(1949,348)$ y por medio de una deliberación racional y de un juicio prudente, alcanza conclusiones a las que la sociedad sólo podría llegar de un modo indirecto y más lentamente. Por ello Burke podía decir:

«Verdaderamente aspiro a estar atento a vuestras opiniones, pero lo haré con respecto a las opiniones que vosotros y yo debemos tener a lo largo de los próximos cinco años. No estaré pendiente del destello de un día.» (Citado según James Hogan, 1945, 189.)

Esta coincidencia entre el resultado de la decisión racional parlamentaria y las opiniones a largo plazo del pueblo se manifiesta en los sentimientos de aprobación de la colectividad con respecto a las decisiones parlamentarias. La gente rara vez se equivoca con relación a sus sentimientos. Sólo cuando intenta especular sobre la base de lo que siente se extravía en la opinión:

«Las criaturas más pobres, iletradas e ignorantes de la tierra son los jueces de una opresión practica. Es una cuestión de pareceres y como tales personas casi siempre han sentido casi todo eso, y no son de una sensibilidad excesivamente viva, son los mejores jueces para una tal cosa. Pero en lo concerniente a la causa real o al remedio apropiado, nunca deberían ser llamadas para que dieran consejo ni sobre lo uno ni sobre lo otro.» (1949, 492 y sig.)

Los pareceres, a diferencia del hecho científico o del interés, son esencialmente personales y la única autoridad fiable acerca de lo que uno siente es uno mismo. De allí que sea importante para la actividad gubernamental que la gente transmita con la mayor precisión posible sus sentimientos:

«El pueblo es el señor. Sólo debe expresar sus necesidades en general y en bruto. Nosotros somos los artistas expertos; somos los trabajadores hábiles para configurar sus deseos en la forma perfecta y adaptar el utensilio al uso... Ellos son los pacientes que cuentan los síntomas del mal; pero nosotros conocemos el lugar exacto donde 
se sitúa la enfermedad y cómo aplicar el remedio.» (Citado según Ernest Barker, 1951, 201.)

La transmisión de estos síntomas se realiza a través de las elecciones, que sirven así como correctivo de posibles desviaciones de los parlamentarios en su calidad de definidores del interés nacional.

La concepción elitista de la representación parlamentaria de Burke se apoyaba en un dato fáctico: la homogeneidad del cuerpo electoral, y en un supuesto gnoseológico: la existencia de verdades políticas descubribles a través del ejercicio de la razón en la deliberación parlamentaria. El criterio de la verdad política es su coincidencia con el interés nacional, corroborado o falseado a través de la expresión de los sentimientos del pueblo en las elecciones.

A finales del segundo decenio del siglo XX, Carl Schmitt, recogiendo en parte la interpretación burkeana y sugerencias de Donoso Cortés acerca de la crisis de la clase burguesa, formuló una de las críticas más duras que se conocen contra el sistema parlamentario. Conviene recordar algunos de sus argumentos centrales.

También Schmitt aceptaba la posibilidad de conocer la verdad política a través de la discusión:

«...de la libre lucha de las opiniones surge la verdad» $(1926,46)$.

Pero el parlamento había dejado de ser el foro donde podía formarse «una voluntad estatal, por encima de los egoísmos de los partidos» $(1931,88)$. Lejos de ser

«el escenario de una negociación libre, unitaria, de libres representantes del pueblo, de transformadores de los intereses partidistas en una voluntad suprapartidista (se ha convertido) en un escenario de la división pluralista de los poderes sociales organizados» $(1931,89)$.

El fracaso del parlamentarismo se debía a

«las inestables y cambiantes de caso en caso mayorías parlamentarias de los numerosos y en todo respecto heterogéneos partidos políticos... la mayoría es siempre una mayoría de coalición y, de acuerdo con los diferentes ámbitos de la lucha política -política exterior, económica, social y cultural- totalmente cambiante» $(1931,88)$.

En esta situación, la discusión racional habría sido sustituida por la negociación y el compromiso: 
«...lo que importa no es encontrar lo racionalmente correcto, sino calcular los intereses y las chances de ganar e imponerlos y hacer valer, dentro de lo posible, el propio interés» (1926, 10).

«Las grandes decisiones políticas y económicas, de las que en la actualidad dependen el destino de los hombres, ya no son el resultado de un equilibrio de opiniones a través del discurso y sus réplicas públicas y tampoco el resultado de debates parlamentarios.» (Ibidem, 62.)

Las decisiones propiamente dichas son tomadas en las comisiones parlamentarias y allí donde se lleva a cabo la evaluación de los intereses de las agrupaciones con poder político y económico. 319.)

«De esta manera, el privilegio de la libertad de discurso pierde su presupuesto.» (1928,

Lo que vale para la discusión, vale también para la publicidad. La costumbre de trabajar en comisiones cada vez más reducidas tiende a reducir también en creciente medida las funciones del plenario parlamentario:

«Los reducidos comités en los cuales se toman las resoluciones ni siquiera son comisiones del parlamento, sino reuniones de dirigentes de los partidos, conversaciones con los mandatarios de los partidos, de las asociaciones de intereses, etc.» $(1928,319$.)

$\mathrm{Si}$, de acuerdo con la concepción liberal originaria, el parlamento era el lugar de la integración política a través de representantes independientes, éstos se habían convertido ahora en simples delegados, en los «embajadores» que criticara Burke. Según Schmitt, lo que primaba en Weimar eran las asociaciones y los partidos rígidamente organizados, con una influyente burocracia, que dependía en su totalidad de intereses contrapuestos. Al desgarramiento pluralista del parlamento se sumaba el fenómeno de la policracia, es decir, la existencia simultánea y confusa de diversos centros autónomos de la vida económica. El sistema policrático, fruto también de la sociedad de masas, carecía, según Schmitt, de una conducción única y de toda coordinación.

La democracia de la sociedad de masas no podía, pues, canalizar la persecución de sus intereses a través de la representación parlamentaria, sino que debía buscar su identidad eliminando las causas de la heterogénea pluralidad. La solución propuesta por Schmitt es de sobra conocida y no he de considerarla aquí. Deseo, en cambio, subrayar tres puntos de la posición Burke-Schmitt: 
1) la afirmación de la existencia de verdades ético-políticas; 2) la convicción de la necesidad de contar con una sociedad homogénea para que pueda funcionar la representación parlamentaria; 3) la relación entre discusión y negociación desde la perspectiva de la satisfacción de los «verdaderos» intereses de las personas.

\section{II}

Si el hilo conductor de la posición Burke-Schmitt era la búsqueda de la verdad política, en Kelsen lo será la afirmación de la libertad individual, es decir, de su autonomía, vinculada con la igualdad esencial de todos los hombres. Justamente la síntesis de estos dos principios es lo que, según Kelsen, caracteriza la democracia. Siguiendo la concepción kantiana, Kelsen considera que la libertad natural de seres iguales es sólo posible si es sustituida por la libertad política; es decir, sólo podemos ser libres si aceptamos el dominio del Estado. Pero, políticamente libre es sólo quien, no obstante ser súbdito del Estado, obedece a su propia voluntad y no a una extraña. Esta absoluta coincidencia de voluntades con respecto a las disposiciones del Estado puede, sin embargo, darse únicamente en la situación hipotética de la fundación del orden político a través del contrato originario. En la realidad de la vida política, el principio de la unanimidad tiene que ser reemplazado por el de la mayoría, en tanto ella significa la mayor aproximación posible a la idea de la libertad.

«Sólo la idea de que -si no todos- al menos el mayor número posible de personas es libre, es decir, que el menor número posible ha de caer en contradicción entre su voluntad y la voluntad general del orden social, permite inferir racionalmente el principio de la mayoría.» (1929, 9 y sig.)

Que la adopción de decisiones de acuerdo con el principio de la mayoría significa una restricción de la libertad de quienes integran la minoría es obvio. Pero que la viabilidad de las democracias en las sociedades con un número apreciablemente grande de miembros tiene que aceptar este tipo de restricciones es también un hecho cierto. En efecto, al no ser posible la democracia directa es necesario recurrir a un sistema de representantes, es decir, a un sistema parlamentario cuya función primordial, según Kelsen, es:

«La formación de la voluntad estatal a través de un órgano colectivo elegido por el pueblo sobre la base del derecho de sufragio 
universal e igual, es decir, democráticamente, y que decide de acuerdo con el principio de la mayoría.» $(1929,28$.

El parlamentarismo constituye un compromiso entre la exigencia democrática de libertad y la división del trabajo impuesto por las modernas sociedades nacionales (1925, 7). Justamente también debido a la complejidad de las sociedades contemporáneas, el «pueblo», en tanto tal, no está en condiciones de practicar la democracia directa y por ello debe limitarse a la creación del órgano que forme la voluntad estatal. Pero, por otra parte, como se desea conservar la apariencia de que en el parlamento se expresa inquebrantablemente la idea de la libertad, se recurre a la ficción de la representación, a la idea de que el parlamento es tan sólo un representante del pueblo y que en el parlamento el pueblo puede expresar su voluntad, a pesar de que en todas las constituciones liberales se acepta el principio del mandato libre del representante, es decir, su no sujeción a instrucciones por parte de los representados. Esta independencia del representante con respecto a los representados es lo que distingue al parlamento moderno de las antiguas representaciones estamentales en donde existía el sistema del mandato imperativo. La representación es, pues, una ficción que pretende legitimar el parlamentarismo desde el punto de vista de la soberanía popular. Este carácter ficticio de la idea de la representación no pasó al primer plano de la conciencia política mientras la democracia estuvo en lucha contra la autocracia y el parlamento no había logrado imponerse totalmente frente al monarca y los estamentos. Pero, una vez que se consumió este triunfo, lo que se puso en tela de juicio fue justamente la viabilidad de esta ficción. Se argumentó entonces que la voluntad que se forma en el parlamento no es la voluntad del pueblo.

Según Kelsen, este argumento es correcto sólo si se intenta justificar la esencia del parlamentarismo a partir de la idea de la libertad y no como un compromiso entre ésta y la división del trabajo.

El eje de este compromiso es el principio de la mayoría vinculado con la protección de la minoría. Conceptualmente, es decir lógicamente, el principio de la mayoría presupone «el derecho de existencia de una minoría» $(1925,31$; 1929, 53). Su protección es la función esencial de la declaración de derechos fundamentales o humanos que contienen las modernas constituciones democrático-liberales:

«El catálogo de los derechos y libertades básicos se convierte, a partir de la protección del individuo frente al Estado, en la protección 
de la minoría... frente a la mayoría absoluta. Esto significa que medidas que afectan ciertas esferas de intereses nacionales, religiosos, económicos o en general espirituales, son sólo posibles con el acuerdo entre la mayoría y la minoría.» $(1929,54$.

Además:

«Lo que importa es que de la tendencia a formar una mayoría... surge el efecto de que finalmente dos grupos se enfrentan en lo esencial y ambos luchan por el poder... La fuerza de la integración social es lo que caracteriza primordialmente al principio de la mayoría desde el punto de vista sociológico.» $(1925,31$, y 1929, 56.)

Si para Carl Schmitt una de las causas de la crisis del parlamentarismo era la sustitución de la discusión por el compromiso negociado, para Kelsen es justamente la obtención del compromiso un aspecto esencial de la democracia parlamentaria:

«Una ligera mirada a la práctica parlamentaria muestra que el principio de la mayoría, justamente dentro del sistema parlamentario, se afianza como un principio del compromiso.» (1925, 31 y sig.)

\section{$\mathrm{Y}$}

«...compromiso significa dejar de lado aquello que separa en aras de aquello que une. Todo canje, todo contrato, es un compromiso, pues contrato ("Vertrag") significa tolerarse ("sich vertragen").» $(1925,31 ; 1929,57$.

La idea de la tolerancia kelseniana se basa en un relativismo axiológico que rechaza la posibilidad de conocer verdades ético-políticas absolutas. La objetividad de los valores es rechazada; compete a cada cual fijar subjetivamente la escala de sus valores. Entre quienes sustentan concepciones subjetivas de los valores, sólo el compromiso tolerante permite una convivencia organizada que no sacrifique totalmente la autonomía de las personas. Es esta actitud de tolerancia basada en un relativismo axiológico lo que permite justificar la democracia:

«Partiendo de la imposibilidad de conocer la verdad absoluta o el valor absoluto y, por tanto, de la incapacidad de pretender para alguna concepción la validez exclusiva, que excluya a todas las demás, por así decirlo, dictatorial, sino siempre dispuesto a considerar al menos como posible la concepción opuesta, el relativismo filosófico impulsa a aquel método dialéctico que tiene que permitir el desarrollo de la opinión y de la contraopinión... ¿No es éste, en el 
fondo el mismo método que el del parlamentarismo democrático con su reconocimiento de los derechos de la minoría y su procedimiento contradictorio, dirigido a la obtención de un compromiso?» (1925, 40 y sig.)

Todo el procedimiento parlamentario está orientado a la búsqueda de una línea entre las concepciones opuestas de la mayoría y la minoría:

«(El procedimiento parlamentario) crea las garantías para que los diferentes intereses de los grupos representados en el parlamento puedan hacer oír su voz, puedan manifestarse en tanto tales en un proceso público. Y si el procedimiento específicamente dialéctico-contradictorio del parlamento tiene algún sentido profundo, éste puede ser tan sólo el que de la contraposición de tesis y antítesis de los intereses políticos pueda producirse alguna síntesis. Pero ésta no puede significar, como suele suponerse falsamente confundiendo la realidad con la ideología del parlamentarismo, una verdad absoluta, "superior", un valor absoluto que se encuentre por encima de los intereses de los grupos, sino un compromiso.» $(1929,58$.

La idea del compromiso refuerza también la concepción kelseniana del principio de la mayoría, que no debe ser identificado con el dominio de la mayoría, tal como la que podrían sustentar las concepciones que propician la dominación absoluta de una clase social integrada por la mayoría de la sociedad.

Desde luego, si la aplicación del principio de la mayoría presupone una cierta base de entendimiento entre mayoría y minoría, ello requiere también un reducido grado de heterogeneidad social. En Kelsen, la garantía de la homogeneidad social está dada por la comunidad cultural y lingüística. Es interesante señalar al respecto que estos dos elementos eran también en la concepción kantiana los fundamentos insustituibles de las unidades nacionales como agentes del sistema internacional. Las diferencias económico-sociales señaladas por el marxismo como grave impedimento para una democracia representativa son desplazadas por Kelsen a segundo plano. Aun en una situación tal, la democracia sigue siendo para Kelsen la única vía posible para superar el peligro de la dictadura:

«Si, como justamente lo subraya la crítica marxista a la llamada democracia burguesa, lo que importa es la relación real de poder, entonces la forma de Estado democrático-parlamentaria, con su doble agrupación esencial de acuerdo con el principio mayoría-minoría, es la "verdadera" expresión de la sociedad actual dividida en dos clases. Y si existe una forma que ofrece una posibilidad de no impulsar 
esta fuerte oposición, que uno puede lamentar pero no negar, a la catástrofe a través de la vía sangrienta y revolucionaria, sino de equilibrarla pacífica y lentamente, ella es la forma de la democracia parlamentaria...» $(1929,68$.

La confianza kelseniana en la posibilidad de evitar una dictadura de clase, como la propuesta por el marxismo, o una dictadura de un «Führer», como la propiciada por Carl Schmitt, en una sociedad dividida por graves diferencias socio-económicas fue puesta en duda por otro gran defensor de la democracia parlamentaria, Hermann Heller, quien propiciara la creación de un Estado social de derecho, justamente para superar la heterogeneidad social. La consideración de su postura puede aquí ser dejada de lado. Deseo más bien subrayar las diferencias entre la posición Burke-Schmitt y la de Kelsen. Son por lo menos, aparentemente, las siguientes: 1) mientras para Burke-Schmitt existen verdades absolutas en el plano de la ética-política, para Kelsen sólo el relativismo axiológico es racionalmente defendible; 2) el núcleo de la actividad parlamentaria está constituido en Kelsen por la negociación y el compromiso, es decir, por aquello que Schmitt consideraba como una forma degenerada de la discusión; 3) la heterogeneidad social, a diferencia de lo que sucede en Burke-Schmitt, no es un hecho que pueda poner en peligro la viabilidad de la democracia representativa, que justamente en estos casos demuestra ser el instrumento más adecuado para asegurar la paz social.

Estas parecen ser las diferencias más notorias que, tomadas literalmente, vuelven irreconciliables ambas posiciones.

Sin embargo, si se ven las cosas más de cerca, es posible hacer una lectura de la posición kelseniana que le resta mucho de su radical relativismo. Por lo pronto, el punto de partida de su defensa del parlamentarismo democrático es la aceptación de dos valores fundamentales: la libertad y la igualdad. Ello explica el recurso kelseniano a la idea de un contrato social hipotéticamente aceptado por unanimidad y al principio de la mayoría basado en el respeto de la minoría. Kelsen defiende la concepción de la democracia formal, pero cabe preguntarse hasta qué punto es puramente formal una democracia que sustenta el respeto de los derechos básicos o humanos como garantía de la existencia de la minoría. Como se ha visto, esta garantía está lógicamente vinculada con el principio de la mayoría que, a su vez, es el que permite la mayor aproximación posible al ideal de la libertad entendida como obediencia a las leyes que cada cual estaría dispuesto a imponerse. Desde este punto de vista, el principio 
de la mayoría no indica un procedimiento vacío que legitimaría el sistema político, cualesquiera que fuesen los resultados que con él puedan obtenerse. Pensar que tal es el caso en la posición de Kelsen sería incluirlo en las filas de quienes, como Niklas Luhmann, sostienen que la existencia de un mero procedimiento es condición necesaria y suficiente para la legitimación de un sistema político.

Kelsen insiste en que la negociación es la esencia de la actividad parlamentaria. Pero esta negociación está enmarcada por la idea de una tolerancia, de un soportarse recíprocamente, conceptualmente vinculada con la idea del contrato, es decir, con la idea de la aceptación hipotética y unánime de una forma de Estado que supere la anarquía sin destruir la autonomía personal. En este sentido, si bien es cierto que la negociación es elemento esencial de la actividad parlamentaria, parecería que -también, según Kelsen- cosas tales como la autonomía de las personas no son negociables. Si se elimina la barrera de lo no negociable y se insiste en la equiparación incondicionada de todas las convicciones morales, ¿cómo se explica la referencia kelseniana al «derecho de existencia de la minoría» que es el que abre la «posibilidad de la protección de la minoría frente a la mayoría» (1925, 31; 1929, 53) y su caracterización de la «función esencial» de los derechos humanos como protección de la minoría frente a la mayoría? El principio de la mayoría, según Kelsen, es justamente el que impide el dominio de una clase sobre otra, es decir, el dominio de la mayoría o la «casualidad de la aritmética» (como dice en 1929, 55; una frase que recuerda el juicio de Jorge Luis Borges sobre la democracia). El razonamiento kelseniano está dirigido precisamente en contra de la identificación del «principio de la mayoría» con el «dominio de la mayoría»; por ello la afirmación de que el principio de la mayoría requiere la existencia de la minoría no es una mera tautología en el sentido de que no puede hablarse de mayoría si no hay minoría.

La confianza kelseniana en la viabilidad del parlamentarismo democrático no obstante la heterogeneidad socio-económica de una determinada sociedad puede también ser puesta en duda sin que ello signifique echar por la borda las ventajas de la representación parlamentaria.

Llegados a este punto, parece aconsejable detenerse a analizar cuál es realmente la justificación ético-política de la representación parlamentaria democrática. Ello nos lleva a la tercera de las cuestiones que quería considerar. 


\section{III}

La cuestión de la justificación ética de la representación parlamentaria se centra en tres puntos básicos: 1) ¿Qué relación debe existir entre representados y representantes? 2) ¿Puede ser sometido a discusión parlamentaria todo tipo de cuestiones? 3) ¿Está éticamente exigida la garantía de un umbral mínimo para la negociación y el compromiso parlamentarios?

El primer punto está vinculado con la relación que existe entre deseos e intereses (Burke) o entre autonomía y gobierno (Kelsen). El segundo hace referencia a la existencia o no de verdades políticas (Burke-Schmitt) o de limitaciones al contenido posible de la discusión-negociación (Kelsen). El tercero apunta al presupuesto de la homogeneidad (Burke-Schmitt).

1. La primera pregunta ha sido respondida por dos tipos diferentes de teorías. Según la primera, la teoría de la delegación o del mandato, el representante debe representar aquello que quiere el representado. Según la segunda, la teoría de la independencia del representante, éste debe representar aquello que responde al interés del representado, con prescindencia de sus deseos actuales.

La primera teoría supone no sólo una relación lógica entre deseo e interés, sino también que nadie es mejor juez que uno mismo con respecto a lo que daña o benefícia los propios intereses. Es la posición de John Stuart Mill:

«...el hombre o la mujer más común tiene (al respecto) medios de conocimiento que superan inconmensurablemente aquellos que puede poseer cualquier otro» $(1978,207)$.

En otro lugar (1987) me he referido a esta tesis radical de Mill contra toda forma de paternalismo jurídico y tratado de demostrar que, como proposición universal, es falsa. No he de exponer aquí los argumentos entonces presentados, sino tan sólo recordar que una definición de cuáles sean los intereses de una persona en una circunstancia determinada o con respecto a una determinada política presupone el conocimiento de los elementos relevantes del caso y la coherencia con respecto a los objetivos deseados y los medios necesarios para alcanzarlos. Burke 
ponía radicalmente en duda la relación entre la satisfacción de lo que la gente quiere y la promoción de sus intereses. Distinguía por ello, como hemos visto, entre opinión y conocimiento de la verdad política, que identificaba con la satisfacción de los intereses de la comunidad.

Sin embargo, podría insistirse en la conveniencia de mantener una relación necesaria entre lo que desea el representado y el comportamiento del representante. Si el fundamento de la justificación del Estado en general y de la representación parlamentaria en particular es el consentimiento que cada persona presta a este tipo de instituciones, el representante no podría ignorar los deseos de sus representados, ya que la autonomía de cada persona se expresa justamente en lo que ella quiere o no quiere. Si dejamos de lado los casos en los que los representados padecen de una incompetencia básica -en los que estaría justificado el paternalismo jurídico-, puede inferirse, aduciría esta posición, que el representante está éticamente obligado a actuar de acuerdo con los deseos de sus representados.

A esto podría a su vez responderse que el razonamiento es correcto sólo que la premisa fáctica de la competencia básica del representado es, por lo general, falsa, ya que éste suele carecer del conocimiento de datos relevantes que posee sólo el representante. Por ello, las propuestas de los representados son, por lo general, meras opiniones, como diría Burke. Su aceptación incondicionada podría conducir a un resultado opuesto al querido. Si se acepta este argumento, podría entonces inferirse que una buena representación es aquella que no pone el acento en los deseos de los representados, sino en sus intereses. El consentimiento de los representados puede conferir legitimidad a los actos del representante sólo si aquéllos poseen la suficiente información y están dispuestos a aceptar criterios no sólo de racionalidad, sino de razonabilidad con respecto a las medidas que proponen. Lo relevante no sería, pues, el consentimiento fáctico, sino un consentimiento hipotético, es decir, el que los representados prestarían si dispusiesen de todas las informaciones relevantes del caso y pudieran participar en la discusión parlamentaria. Este es el argumento fuerte de quienes sostienen el principio de la libertad del representante en la búsqueda de la satisfacción de los intereses reales de los representados.

Esta posición tiene a su favor una innegable dosis de realismo por lo que respecta a la relación entre los deseos de personas deficientemente informadas, tal como es el caso en las complejas sociedades modernas, y la satisfacción cabal de sus necesidades. Deja abierta, sin embargo, la puerta a un paternalismo legislativo 
injustificable que, so pretexto de conocer siempre mejor los intereses de la gente que los propios afectados, puede fácilmente degenerar en una permanente intervención en los planes de vida individuales, con lo que se lesionaría la autonomía de la persona.

Los problemas que traen aparejadas estas dos posiciones extremas aconsejan buscar una vía intermedia sobre la que habré de volver más adelante. Antes deseo considerar el segundo de los puntos indicados, es decir, si puede ser sometido a la discusión parlamentaria todo tipo de cuestiones.

2. Sea que se considere que la discusión parlamentaria es el medio adecuado para encontrar la verdad política (Burke) o que la negociación y el compromiso constituyen la mejor aproximación posible al ideal de la libertad y de la igualdad (Kelsen), no parece que existan cuestiones que puedan, en principio, ser excluidas de la deliberación parlamentaria.

Sin embargo, esta apertura irrestricta resulta no ser sostenida ni por Burke ni por Kelsen. En Burke existe el límite impuesto por el presupuesto del respeto a la propiedad burguesa. Además, sólo está permitido adoptar aquellas medidas que son verdaderas, es decir, que satisfacen el interés de la totalidad. En Kelsen, el ejercicio del principio de la mayoría está limitado por el respeto de los derechos de la minoría a los que significativamente llama derechos fundamentales o humanos. Las situaciones de discusión y de negociación recuerdan las situaciones de mercado descritas por los economistas, en las que los individuos pueden tener en cuenta las preferencias subjetivas de los demás y decidir, sobre la base de los diferentes costos, los cursos de acción que desean adoptar. Pero también en las relaciones de mercado existe consenso en el sentido de que ellas pueden funcionar sólo si, por lo pronto, se presupone el respeto de ciertos valores básicos como son la individualidad y la libertad de elección. Pero no sólo esto: quienes propician el modelo del mercado y la idea de la negociación y el compromiso que aquél implica, admiten que es necesario excluir del juego del mercado aquellos bienes que son considerados como básicos para la realización de todo plan de vida.

En este sentido, la exclusión de algunos temas básicos de la negociación parlamentaria o del ámbito del mercado parece estar éticamente impuesta. Con respecto a cuáles deben ser estos temas, y cuál es el criterio de exclusión, mi propuesta es la siguiente: a) Deben ser excluidos de la negociación y el compromiso parlamentarios todos aquellos bienes que son considerados como básicos para la realización de todo plan de vida.

b) La determinación de este campo de exclusión no puede 
quedar librada al consenso fáctico ni de los representados ni de los representantes. El consenso fáctico determina sólo el campo de la moral positiva de una determinada colectividad en un determinado momento de su historia. Del hecho de que los miembros de una colectividad coincidan en la aceptación de determinadas pautas de comportamiento no se infiere sin más que ellas están también permitidas desde el punto de vista de una moral esclarecida o ética. La fundamentación racional de las normas morales requiere recurrir al artificio de situaciones hipotéticas en las que se aceptan criterios marco como son los de la imparcialidad y la universalidad.

c) Por lo que respecta a la vigencia efectiva de los derechos en el «coto vedado» de los bienes básicos, es indiferente la voluntad o deseos de los integrantes de la comunidad. Aquí está plenamente justificada una actitud paternalista en el caso de que los miembros de la comunidad no comprendan la importancia de estos bienes básicos. Y ello es así porque la no aceptación de la garantía de los propios bienes básicos es una clara señal de irracionalidad o de ignorancia de relaciones causales elementales como son las que existen entre la disponibilidad de estos bienes y la realización de cualquier plan de vida. En ambos casos, quien no comprende la relevancia de los bienes básicos puede ser incluido en la categoría de incompetente básico.

d) Si se acepta lo dicho en el párrafo anterior, hay que aceptar también que, con respecto a los bienes básicos, para quien o quienes los defiendan no rige el «principio de no dictadura» tal como lo formulara Kenneth J. Arrow: «No existe ningún individuo cuyas preferencias son automáticamente las preferencias de la sociedad, independientemente de las preferencias de todos los otros individuos.» $(1967,226$.) Pienso que quien, por ejemplo, en la Alemania nazi, se oponía a los propósitos de Hitler, tenía a su favor una innegable justificación ética de la que carecía la opinión mayoritaria y estaba también éticamente autorizado a imponer su posición, en contra de aquélla (cfr. sobre este tema, Otfried Höffe, 1980). El dejar de lado en estos casos el principio de no dictadura en el sentido de Arrow es justamente el punto de partida para combatir dictaduras como las fascistas o todas aquellas en las que el dominio de la mayoría ha sustituido al principio de la mayoría (para usar la terminología kelseniana).

e) Si se admite, como creo que es correcto, la tendencia a la expansión de la ética, no es aventurado afirmar que el coto vedado de los bienes básicos tiene también una tendencia a la expansión. Ella puede estar determinada por un doble tipo de factores: 1) factores de tipo cognitivo, es decir, la intelección de que 
algunas conclusiones, hasta ahora no percibidas, pueden ser inferidas de las premisas del sistema ético. Creo que esto es lo que sucede cuando se habla de diferentes generaciones de derechos humanos. No se trata aquí de la inclusión de nuevas premisas, sino de inferir conclusiones de premisas ya aceptadas. Basta pensar, por ejemplo, en la relación que existe entre el derecho a la vida (derecho humano de la llamada «primera generación») y el derecho a un medio ambiente no contaminado (derecho de la «tercera generación») o la que existe entre el deber negativo de no dañar y el deber positivo de no omitir ayuda cuando se puede así evitar un daño. Pero 2) existen también factores materiales de disposición de recursos económicos, técnicos o culturales que pueden requerir correr los límites del coto vedado.

f) Tomando en cuenta estas limitaciones, el ámbito de la gestión del representante es, por una parte, el del afianzamiento de la vigencia efectiva de los bienes básicos. Se trata aquí de la defensa de los bienes primarios (Rawls) o de los intereses universalizables (Habermas). Pero también es el campo de la negociación y el compromiso, es aquel que, siguiendo una propuesta de James O. Grunebaum (1981), puede ser llamado el ámbito de los deseos secundarios de la gente, es decir, aquellos que no están relacionados con bienes primarios. Aquí rige el principio de respetar los deseos de los representados, con la cláusula cautelar que dice: «Deberán satisfacerse los deseos secundarios de los representados siempre que, sobre la base de la información de que dispone el representante, su satisfacción no implique el sacrificio de algún bien básico o la frustración de deseos secundarios que los propios representados valoran más que el deseo secundario de cuya satisfacción se trata.» Por ejemplo, supongamos que la satisfacción del deseo secundario $\mathrm{d}_{1}$, la construcción de una fábrica en una determinada zona, produzca una contaminación ambiental tal que pone en peligro el bien básico de la salud de los pueblos vecinos o que a la construcción de la fábrica, aun en el caso de que no sea contaminante, se oponga uno de los socios de la coalición gubernamental del partido que propone la construcción y amenace con retirarse de la coalición con la consiguiente frustración de otro deseo secundario $\mathrm{d}_{2}$, de los miembros del partido pro fábrica, cual es el permanecer en el gobierno y que ellos mismos valoran más que $\mathrm{d}_{1}$. En ambos casos, la cláusula cautelar prohibiría la insistencia en el proyecto.

El campo de la negociación y el compromiso es el ámbito adecuado para la persecución de los intereses secundarios, sobre la base de la evaluación de costos y beneficios. El representante está aquí sujeto a la obligación ética de procurar la mayor satisfacción 
posible de los deseos secundarios de los representados, con las limitaciones señaladas. Su estrategia de negociación y compromiso estará guiada por razones propias del hombre prudente. Para decirlo con palabras de David P. Gauthier:

«Desea atemperar la persecución unilateral de la ventaja aceptando la obligación de adherir a los compromisos adoptados prudencialmente. No se interesa realmente por las ventajas de los demás, que podría llevarlo a modificar la persecución de la ventaja cuando ella entra en conflicto con similares propósitos de los demás. A menos que espere ganar, no desea aceptar restricciones en la persecución de ventajas que aspiran a igualar las oportunidades abiertas a todos. Con otras palabras, no se interesa por la equidad.» (1978, 196.)

Pero, admitiendo que el campo de la negociación y el compromiso está sujeto a consideraciones prudenciales, de costo-beneficio, queda todavía pendiente la cuestión de saber si este ámbito de lo prudencial no requiere un cierto umbral que debe ser proporcionado también sobre la base de consideraciones éticas. Esto me lleva al tercero de los puntos que quería tratar.

3. Como el campo de la negociación y el compromiso es un ámbito que presenta grandes similitudes con el del mercado, pienso que aquí pueden ser de interés las consideraciones de los economistas y de los juristas que se han acercado a estos temas tomando en cuenta reflexiones de aquéllos.

Hasta economistas profundamente liberales como James Buchanan consideran que las negociaciones en el mercado tienen sentido si quienes participan en ellas tienen, por lo menos, la esperanza de tener éxito.

«La "esperanza" es un componente extremadamente importante de cualquier orden social que pretenda ser "justo".» $(1986,135$ y sig.)

Esta posibilidad de éxito no está referida a factores tales como la suerte o el propio empeño sino a la igualdad de derechos con los que las personas entran en el juego de la negociación mercantil:

«Pocas personas podrían decir que el juego económico es intrínsecamente no equitativo porque algunas tienen suerte o hacen mejores elecciones o dedican más esfuerzos que otras. La no equidad en el juego económico descrito por la operación de las instituciones del mercado... tiende a ser atribuida a la distribución de los derechos con los que las personas entran en el juego, antes de que se hagan 
las elecciones, antes de que la suerte lance el dado económico, antes de que se realice esfuerzo alguno.» $(1986,129$ y sig.)

Hermann Heller, al insistir en la necesidad de la homogeneidad social como condición necesaria para el funcionamiento de la democracia parlamentaria, subrayaba también la importancia de la esperanza en la posibilidad de negociaciones exitosas para todas las partes:

«Sólo si el proletariado llega a creer que la igualdad de derechos democrática de su adversario superpoderoso conduce bajo formas democráticas a un callejón sin salida, sólo entonces irrumpirá la dictadura.» (1971, II, 430.)

La falta de confianza del proletariado en las reglas del juego democrático era, según Heller, el resultado de una disparidad social que convertía al summum jus en summa injuria.

También Jürgen Habermas (1977), al distinguir entre intereses universalizables (es decir, éticamente justificables a través del discurso) y no unversalizables o particulares, admite una vía de justificación ética indirecta de estos últimos bajo la forma del compromiso:

«Llamamos compromiso a un equilibrio normado entre intereses particulares que se produce bajo condiciones de un equilibrio de poder entre las partes.» $(1977,154$.

Si no se cumple la condición del equilibrio de poder, el arreglo entre las partes es tan sólo un pseudocompromiso o, para utilizar la terminología de Habermas, una «forma ideológica de justificación» $(1977,155)$ que conduce a un sistema normativo basado tan sólo en la violencia.

La negociación y el compromiso requieren, pues, una igualdad aproximada de recursos jurídicos y políticos. En este sentido, la negociación parlamentaria presupone, para ser éticamente aceptable, una cierta homogeneidad que permita alentar la esperanza del éxito, a la que aluden Buchanan y Heller.

Si esto es así, es necesario contar con algún criterio que permita determinar cuándo una sociedad es homogénea a fin de que el compromiso sea equitativo y todos los grupos sociales se sepan integrables a través de la actividad parlamentaria. Al respecto, mi propuesta es la siguiente:

Una sociedad es homogénea cuando todos sus miembros gozan de los derechos incluidos en el coto vedado de los bienes básicos. 
Cuando tal no es el caso, el principio de la mayoría se transforma en dominio de la mayoría (Kelsen) o constituye una forma ideológica de justificación del poder normativo (Habermas). Ya en el siglo XIX, Abraham Lincoln decía: «Si por la mera fuerza de los números, una mayoría priva a la minoría de algún derecho constitucional claramente escrito, esto puede justificar, desde el punto de vista moral, la revolución.» Argumentos similares han sido utilizados en el siglo XX también para justificar ética, política y jurídicamente fenómenos tales como los de la desobediencia civil.

La exigencia del umbral de homogeneidad es obvia si se piensa que la representación parlamentaria, impuesta por la división del trabajo, es la única forma viable de la democracia en las sociedades actuales y que ésta es el mejor candidato a una justificación ética cuando no se reduce a la aplicación de un procedimiento sino que incluye el ingrediente normativo del respeto a la libertad y la igualdad. Es esto justamente lo que le permite a Kelsen iniciar su razonamiento de justificación de la democracia a partir de la libertad natural y su transformación contractual en la libertad política: idea sustentada no sólo por Kant sino por Rousseau:

«...lo que el hombre pierde por el contrato social es su libertad natural... lo que gana es la libertad civil... se podría agregar a lo adquirido por el estado civil la libertad moral, la única que verdaderamente hace al hombre dueño de sí mismo...» (1964, III, 364 y sig.)

Burke sostenía también la idea de la homogeneidad, sólo que la reducía a la opinión pública británica de 400.000 electores. Carl Schmitt convirtió la exigencia de homogeneidad en la comunidad de la sangre y el suelo y vio su manifestación suprema en la identidad con el «Führer». Kelsen introdujo la limitación de los derechos de la mayoría como exigencia conceptual del principio de la negociación parlamentaria. Y a pesar de que no insistía en la homogeneidad, con su defensa de los derechos fundamentales apuntaba también a la creación de las condiciones iniciales de negociación similares a las que aquí he propuesto.

Llego así al final con una conclusión si se quiere banal: la representación parlamentaria es éticamente justificable cuando respeta la vigencia de los derechos de cada cual a los bienes primarios y procura satisfacer a través del compromiso la realización de los deseos secundarios de los miembros de una comunidad política. Pero quizás haya sido necesario el rodeo del análisis de los argumentos de Burke, Schmitt y Kelsen para que se hiciera patente esta verdad obvia que lamentablemente dista 
mucho de ser una banalidad vivida en grandes partes de nuestro mundo.

Desde el punto de vista jurídico positivo, la conclusión, también obvia, es que los derechos incluidos en el coto vedado de los intereses universalizables o derechos humanos, no pueden ser objeto de recortes productos de negociaciones parlamentarias. Ellos constituyen el núcleo no negociable de una constitución democrático-liberal que propicie el Estado social de derecho. Para el coto vedado vale la prohibición de reforma (como la establecida por el artículo 79, 3 de la Ley Fundamental alemana) y el mandato de adopción de medidas tendientes a su plena vigencia.

Lo aquí expuesto no pretende agotar la problemática de la representación parlamentaria por lo que respecta a posibles situaciones de conflicto relacionadas con la vigencia plena de los bienes primarios. Son concebibles, por lo menos, dos fuentes posibles de conflictos: 1) que no sea posible la satisfacción simultánea de dos bienes básicos; 2) que algún bien básico no pueda ser satisfecho por falta de recursos económicos. En el primer caso, la decisión que al respecto adopten los parlamentarios estará guiada posiblemente por criterios tendientes a evitar el mal mayor. Si se acepta que «negociación» es un término técnico que no vale para el caso de intereses universalizables (como son los bienes primarios), no cabría hablar aquí estrictamente de «compromiso» sino de una decisión tomada bajo aquellas condiciones que caracterizan una «elección trágica». En el segundo caso, si se acepta el principio kantiano, según el cual «deber implica poder ser o hacer», es evidente que la obligación ética queda suspendida hasta que se den las condiciones adecuadas para su implementación. Pero lo importante es tener en cuenta que, en ambos casos, quien o quienes aleguen la situación de elección trágica o de falta de recursos tienen que asumir la carga de la prueba en el sentido de demostrar empíricamente que tal es el caso. Esta imposición pienso que no es trivial, dada la propiedad disposicional de los políticos a justificar la no vigencia plena de los derechos del coto vedado con el argumento de la elección trágica o de la falta de recursos.

$\mathrm{Y}$ por supuesto que también puede objetarse que esta propuesta es demasiado exigente y que son pocos los regímenes políticos que la satisfacen. Es verdad; pero este es un argumento similar al de quien sostiene que la ética suele imponer condiciones severas al comportamiento individual y que hay pocas personas que las satisfacen cabalmente. A esto tan sólo puedo responder con un «¡vaya novedad; peor para ellas!» 


\section{BIBLIOGRAFÍA}

Arrow, Kenneth J. (1967), «Values and Collective Decision-Making», en Peter Laslett y W. G. Runciman (eds.), Philosophy, Politics and Society, Third Series, Oxford.

Barker, Ernest (1951), Essays on Government, Glencoe (III).

Buchanan, James M. (1986), Liberty, Market and State, Oxford.

Burke, Edmund (1949), Burke's Politics, Nueva York.

Garzón Valdés, Ernesto (1987), «¿Es éticamente justificable el paternalismo jurídico?», en Revista latinoamericana de filosofía, vol. XIII, núm. 3, Buenos Aires.

Gauthier, David P. (1978), «Morality and Advantage», en Joseph Raz, Practical Reasoning, Oxford.

Grunebaum, James O. (1981), «What Ought the Representative Represent?», en Norman E. Bowie (ed.), Ethical Issues in Government, Filadelfia.

Habermas, Jürgen (1977), Legitimationsprobleme im Spätkapitalismus, Francfort del Meno.

Heller, Hermann (1971), Gesammelte Schriften, Leiden.

Höffe, Otfried (1980), «Entscheidungstheoretische Denkfiguren und die Begründung von Recht», en Argumentation und Recht, ARSP, Beiheft, número 14.

Hogan, James (1945), Election and Representation, Cork University Press.

Kelsen, Hans (1925), Das Problem des Parlamentarismus, Viena/Leipzig.

- (1929), Vom Wesen und Wert der Demokratie, Tubinga.

Mill, John Stuart (1978), On Liberty, Glasgow.

Rousseau, J. J. (1964), Oeuvres complètes, París.

Schmitt, Carl (1926), Die Geistesgeschichtliche Lage des heutigen Parlamentarismus, Munich/Leipzig.

- (1928), Verfassungslehre, Munich/Leipzig.

— (1931), Der Hüter der Verfassung, Tubinga. 